\title{
Effects of $\beta$-mannanase and bacteriophage supplementation on health and growth performance of Holstein calves
}

Sinyong Jeong ${ }^{1}$, Junsung Lee ${ }^{1}$, Namchul Jo ${ }^{1}$, Jung-Jin Lee ${ }^{2}$, Jae-Hwan Lee ${ }^{2}$, Dong-Keun Kam $^{3}$, Jakyeom Seo ${ }^{1, a}$, Ermias Kebreab ${ }^{4}$, and Seongwon Seo ${ }^{1^{*}}$

${ }^{1}$ Division of Animal and Dairy Sciences, Chungnam National University, Daejeon 34143, Republic of Korea

${ }^{2}$ CTCBIO, Inc., Seoul 05724, Republic of Korea

${ }^{3}$ Cargill Agri Purina, Inc., Seongnam, Gyeonggi 13630, Republic of Korea

${ }^{4}$ Department of Animal Science, University of California, Davis 95616, USA

${ }^{a}$ Present address: Department of Animal Science, Pusan National University, Miryang, Gyeongnam 50463, Republic of Korea

* Correspondence:

Seongwon Seo

swseo@cnu.kr 
Simple Summary: For sustainable animal agriculture, we need to find ways to increase growth efficiency without using feed antibiotics. Bacteriophage, only harmful for specific bacterial strains, has been suggested as a feed additive replacing antibiotics. $\beta$-mannanase, which degrades mannan, is known to promote nutrient digestibility, animal growth, or both, thus improving feed efficiency. The objective of this study was to evaluate the effects of dietary supplementation with bacteriophage and $\beta$-mannanase on health and growth performance in calves. We assigned 36 pre-weaning male Holstein calves to one of four treatments: no supplementation, $0.1 \% \beta$ mannanase, $0.1 \%$ bacteriophage, and both $0.1 \%$ bacteriophage and $\beta$-mannanase supplementation in a starter. Compared to unsupplemented, the bacteriophage supplemented group showed a tendency to improve the survival rate without growth promotion. $\beta$-mannanase supplementation, on the other hand, increased the starter intake and the weekly BW gain and tended to increase the final body weight (BW). Our study indicated that bacteriophage supplementation has a positive effect on survival rate, while $\beta$-mannanase supplementation improves growth performance in calves.

\begin{abstract}
The objective of this study was to evaluate the effects of dietary supplementation with bacteriophage and $\beta$-mannanase on health and growth performance in calves. Thirty-six preweaning male Holstein calves were randomly allocated to one of four dietary treatments: no supplementation, $0.1 \% \beta$-mannanase, $0.1 \%$ bacteriophage, and both $0.1 \%$ bacteriophage and $\beta$ mannanase supplementation in a starter. The experiment lasted from 2 weeks before weaning to 8 weeks after weaning. Twenty-two calves survived to the end of the experiment. No interaction was observed between the two methods of supplementation. A 1-kg increase in initial BW
\end{abstract}


resulted in a 1.41-fold increase in the odds ratio of survival $(p<0.01)$. The bacteriophage supplementation tended to increase the odds ratio of survival $(p=0.09)$. The number of Escherichia coli in feces significantly decreased one week after weaning. $\beta$-mannanase supplementation increased the concentrates intake $(p<0.01)$ and tended to increase the final BW $(p=0.08)$. Analysis of repeated measures indicated $\beta$-mannanase supplementation increased weekly body weight gain $(p=0.018)$. We conclude that bacteriophage supplementation may have a positive effect on calf survival rate, while $\beta$-mannanase supplementation may increase the growth rate and intake of a starter in calves.

Keywords: $\beta$-mannanase, bacteriophage, calf, growth, survival

\section{Introduction}

Diarrhea and respiratory disease are the main causes of death in calves [1] and are caused by infection with viral and bacterial pathogens [2]. Calf mortality rate is higher in winter than in summer [3], mainly due to cold temperatures and poor ventilation [4]. Supplementation with antibiotics help to prevent disease and promote growth in livestock [5]. However, several countries have restricted the use of antibiotics in the diets of livestock [6] and some others in the process of banning antibiotics due to concern for antimicrobial resistance.

Several studies have been conducted to develop feed additives to replace antibiotics. For example, bacteriophages can repress the growth of specific or narrow groups of bacteria [7]. Bacteriophages multiply in bacteria by exploiting the biosynthetic machinery of the host [7]. Bacteriophages have shown the potential for various applications for human and animal health $[7,8]$. However, few studies have investigated the use of bacteriophages as a feed additive for 
ruminants. Prebiotics, such as mannan oligosaccharides (MOS), can also be added to the diet to enhance the health-improving activities of gut microbes. The MOS can be produced by hydrolysis of mannan in feed by supplementation of $\beta$-mannanase, which can indirectly provide MOS to animals. Supplementation of $\beta$-mannanase in a diet improved feed utilization and animal performance in chicken $[10,11]$, pigs $[12,13]$, and ruminants [14-16]. Thus, the objective of the present study was to investigate the effects of bacteriophage and $\beta$-mannanase supplementation on health, growth performance, intestinal pathogenic bacteria, and survival rate of calves reared in winter.

\section{Materials and Methods}

This study was conducted at the Center for Animal Science Research, Chungnam National University, Korea. Animal use and experimental protocols were reviewed and pre-approved by the Chungnam National University Animal Research Ethics Committee (approval number CNU00188).

\subsection{Animals and housing}

A total of 36 Holstein male calves $[45.1 \pm 7.30 \mathrm{~kg}$ of body weight (BW), average 3 to 4 -week old] were purchased from several commercial dairy farms and used in this study. The calves were housed in individual wood pens (1.2-m width $\times 1.4-\mathrm{m}$ length $\times 1.2-\mathrm{m}$ height $)$ at the Center for Animal Science Research, Chungnam National University. Pens were designed to prevent physical contact between calves but allow visual and auditory contact. The front of each pen had two openings for access to pails (diameter $=34 \mathrm{~cm}$, height $=29 \mathrm{~cm}$ ) mounted on the outside. The first 
7 days were used to adapt the calves to the diet by providing them free access to feed and water in individual indoor pens bedded with straw. During the experimental period, the pens were bedded with copra meal pellet. The bedding was replaced every 2 weeks throughout the experimental period.

\subsection{Experimental design and diets}

The experiment was carried out with 1-week adaptation and 10-week experimental periods. The experimental periods included 2 weeks prior to weaning and 8 weeks after weaning. Calves were divided into four groups and used in a balanced and completely randomized design with a 2 $\times 2$ factorial arrangement. The dietary treatments were as follows: 1) control diet with neither supplementation $(\mathrm{CON}), 2$ ) no bacteriophage but $0.1 \% \beta$-mannanase (EZ), 3) $0.1 \%$ bacteriophage but no $\beta$-mannanase (BP), and 4) both $0.1 \%$ bacteriophage and $\beta$-mannanase supplementation (BP_EZ) in a calf starter. The bacteriophage and $\beta$-mannanase used in this experiment were commercial feed additive BacterPhage C (CTCBIO, Inc., Seoul, Korea) and CTCZYME (CTCBIO, Inc., Seoul, Korea), respectively. BacterPhage $\mathrm{C}$ was composed of various bacteriophages targeting Salmonella typhimurium, Salmonella enteritidis, Salmonella dublin, Salmonella derby, Staphylococcus aureus, Escherichia coli $\mathrm{k} 99$ and f41, and Clostridium perfringens type A and C. CTCZYME contains Endo 1-4 $\beta$-mannanase $(800,000 \mathrm{U} / \mathrm{kg})$, which is produced using a patented strain of Bacillus subtills WL-7 (patent 100477456; CTCBIO, Inc., Seoul, Korea).

During the adaptation period, the calves were fed only a commercial milk replacer [Telilac; LNB International Feed B. V., Nisterlrode, Netherlands; $21 \%$ CP, 16\% crude fat (CF)], at 10\% BW. After the one-week adaptation, the calf starter and Timothy hay (Table 1) were offered in addition 
ad libitum before weaning, and thus, the feeding of the experimental diets started 2 weeks before weaning. The amount of milk replacer was progressively reduced from 5 days before weaning. From 1 week after weaning, the amount of starter was restricted to $1.5 \% \mathrm{BW}$ to prevent digestive disorders and enhance forage intake. The calves were fed twice daily at $0800 \mathrm{~h}$ and $1800 \mathrm{~h}$ with equal amounts of each meal. Drinking water was freely accessible to calves throughout the experimental period. Individual daily dry matter intake (DMI) was recorded by measuring the feed offered and the feed refused. BW was measured before morning feeding at the start of the experimental period, 2 weeks before weaning, at weaning, and weekly thereafter.

\subsection{Enumeration of intestinal pathogenic bacteria}

Fecal samples were collected directly from the rectum following BW measurements 2 weeks before weaning, at weaning, and weekly thereafter. Collected fecal samples were placed on ice, transferred to the laboratory, and stored at $-80^{\circ} \mathrm{C}$ until analysis. One-gram of feces was diluted in $9 \mathrm{~mL}$ of phosphate-buffered saline (PBS) and homogenized by vortexing. Serial dilutions in PBS were plated in triplicate on the following selective media: eosin methylene blue agar (EMB agar, Oxoid Ltd., Basingstoke, UK), Salmonella Shigella agar (SS agar, Difco Laboratories, Detroit, MI), and Perfringens agar (OPSP agar, Oxoid Ltd., Basingstoke, UK), which were used to isolate E. coli, Salmonella spp., and C. perfringens, respectively. All plates were incubated in an anaerobic chamber (Coy Laboratory Products Inc., Ann Arbor, MI). E. coli and Salmonella spp. were incubated for $24 \mathrm{~h}$ at $37^{\circ} \mathrm{C}$ and C. perfringens was incubated for $18-24 \mathrm{~h}$ at $35^{\circ} \mathrm{C}$. On the EMB agar, colonies with a metallic green sheen were suspected to be $E$. coli and were counted. Colonies of Salmonella spp. on the SS agar had black centers without color and were counted. $C$. 
perfringens produces black colonies on Perfringens agar.

\subsection{Hematological parameters}

Before the beginning of the experiment, blood samples were taken from the jugular veins of all calves into a Vacutainer tube containing EDTA (Becton Dickinson Vacutainer Systems, Plymouth, UK). Approximately 2-mL blood samples were analyzed for initial immunoglobulin G (IgG) using Bovine IgG ELISA Core Kit (Koma Biotech, Seoul, Korea). After that, blood samples were taken from the jugular veins of 16 calves, which included four calves randomly selected from each treatment group. A total of six samples were taken from each calf throughout the experiment: 2 weeks before weaning, at weaning, and 1,2, 5, and 8 weeks after weaning. Approximately 10-mL blood sample was taken from the jugular vein and collected into a Vacutainer tube containing EDTA (Becton Dickinson Vacutainer Systems, Plymouth, UK) before morning feeding. The tubes were placed on ice, and then immediately transferred to the analytical laboratory of the Animal Hospital at Chungnam National University for complete blood count (CBC) analysis.

\subsection{Chemical analysis}

Feed samples were ground through a cyclone mill (Foss, Hillerød, Denmark), which fitted with a 1-mm screen prior to chemical analysis. Contents of dry matter (DM \#934.01), crude protein (CP; \#976.05), ether extract (EE; \#920.39), acid detergent fiber (ADF; \#973.18), and ash (\#942.05) were determined as previously described AOAC [17]. CP was calculated as 6.25 times the nitrogen content, and total nitrogen was measured by the Kjeldahl method using a DK 20 
Heating Digester and Semi-Automatic Distillation Unit Model UDK 139 (VELP Scientifica, Usmate, Italy). NDF was analyzed using a heat stable amylase and expressed inclusive of residual ash (aNDF) as described by Van Soest, et al. [18].

\subsection{Statistical analysis}

Data were analyzed using the MIXED procedure in SAS (SAS Institute Inc., Cary, NC) for comparison of means. The linear model was as follows:

$$
y_{i j}=\mu+\tau_{i}+e_{i j}
$$

where, $y_{i j k}$ is $\mathrm{jth}$ observation $(\mathrm{j}=1-12)$ in $i$ th treatment $(\mathrm{i}=1-4), \mu$ is the overall mean, $\tau_{i}$ is the fixed effect of the $i$ th treatment, and $e_{i j}$ is the unexplained random effect on the $j$ th observation in the $i$ th treatment.

Three orthogonal contrasts were tested: the difference with or without bacteriophage supplementation (i.e., $\mathrm{CON}$ and $\mathrm{EZ}$ versus BP and BP_EZ), the difference with or without $\beta$ mannanase supplementation (i.e., $\mathrm{CON}$ and BP versus EZ and BP_EZ), and the interaction between bacteriophage and $\beta$-mannanase supplementation (i.e., CON and BP_EZ versus EZ and BP). When no interaction was observed, we further tested the main effect of the two supplementations orthogonally without considering the interaction between them [19].

The effects of treatments on BW and hematological parameters were analyzed using the MIXED procedure with repeated measures. Initial values were included in the model as covariates in each analysis. The best variance-covariance structures for each analysis were unstructured, UN, and auto-regression, $\mathrm{AR}(1)$, for $\mathrm{BW}$ and hematological parameters, respectively, as assessed by the Akaike information criterion (AIC) and the Bayesian information criterion (BIC). In the BW 
analysis, the treatment $\times$ week interaction, body weight gain $(\mathrm{BWG}, \mathrm{kg} /$ week), was of particular interest. To estimate the effects of bacteriophage and $\beta$-mannanase supplementation on survival rate, we used the logistic procedure in SAS to estimate the strength of the association between each variable and death based on the odds. Pair-wise comparisons of the least square means were conducted using the PDIFF option with Tukey-Kramer adjustment when there was a significant overall treatment effect. Significance was declared at $P<0.05$, and a trend was discussed at 0.05 $\leq P<0.1$.

\section{Results}

\subsection{Effects of supplementation of bacteriophage}

Twenty-two calves survived to the end of the experiment. Among the treatments, five, four, seven, and six calves survived in the CON, EZ, BP, and BP_EZ groups, respectively. No calves died later than 2 weeks post-weaning. Although not statistically significant $(p=0.21)$, the bacteriophage supplemented group (BP and BP_EZ) showed a numerical increase in calf survival rate, which was defined as the number of surviving calves as a percentage of the total number of calves at the beginning of the experiment, compared to the bacteriophage unsupplemented group $(\mathrm{CON}$ and EZ). After weaning, the survival rate rapidly declined in the bacteriophage unsupplemented group, compared to that in the bacteriophage supplemented group (Figure 1). Up to 2 weeks after weaning, $50 \%$ of the calves in the bacteriophage unsupplemented group survived, while $70 \%$ of the calves in the bacteriophage supplemented group survived.

Differences in the odds ratio of survival between the bacteriophage unsupplemented and supplemented groups were also compared using the logistic procedure with initial BW as a 
covariate. Initial BW significantly affected the odds ratio of survival. The estimated effect of initial BW on the odds ratio of survival was $1.41(p<0.01)$. Therefore, a 1-kg increase in BW 2 weeks before weaning resulted in a 1.41-fold increase in survival. Accounting for differences in the initial BW of the calves, the odds ratio of survival tended to increase approximately 6.15 -fold in the bacteriophage supplemented group $(p=0.09)$.

\subsection{Effects of supplementation of $\beta$-mannanase}

No significant differences were observed between treatments for the initial BW, BW at weaning, and final BW of calves (Table 2). In contrast, comparisons showed that the calves supplemented with $\beta$-mannanase tended to have a heavier final $\mathrm{BW}(p=0.08)$ than those unsupplemented with $\beta$-mannanase. Total DMI did not differ among the treatment groups $(p>$ 0.10); however, the DMI of concentrates was significantly increased by $\beta$-mannanase supplementation $(p<0.01)$. Forage DMI tended to decrease when the calves were fed a diet supplemented with bacteriophage $(p=0.07)$. No significant differences were observed between treatments for feed efficiency, or the average daily gain $(\mathrm{g})$ to DMI $(\mathrm{g})$ ratio, $(p>0.05)$.

The effects of dietary treatments on changes in BW were analyzed using the 22 surviving calves. In contrast to the health of the calves, no trend was observed for the effect of bacteriophage supplementation on growth by orthogonal contrasts analysis; however, BWG was significantly greater in the $\beta$-mannanase supplemented group $(p=0.018)$. The estimated BWG was 3.05 and $4.09 \mathrm{~kg} /$ week, equivalent to 436 and $584 \mathrm{~g} / \mathrm{d}$, in the $\beta$-mannanase unsupplemented and supplemented groups, respectively (Figure 2). 


\subsection{Intestinal pathogenic bacteria and hematological parameters}

The total number of fecal $E$. coli decreased linearly throughout the experimental period ( $p<$ 0.01, Figure 3). Among treatments, there was a significant difference in the number of E. coli 1 week after weaning $(p=0.01)$. After 1-week weaning, the bacteriophage supplemented group had a significantly reduced population of $E$. coli in feces compared with the bacteriophage unsupplemented group (3.5 versus $4.7 \log \mathrm{CFU} / \mathrm{g}, p<0.01$ ). Thereafter, no difference between groups was found. Salmonella spp. and C. perfringens were barely detectable in fecal samples from calves throughout the experimental period (data not shown).

Most of the tested hematological parameters were not significantly different among the treatment groups; however, the lymphocyte concentration and the neutrophil to lymphocyte (N:L) ratio tended to differ by treatment ( $p=0.07$ and 0.08 , respectively; Table 3 ). This was due to the interaction between $\beta$-mannanase and bacteriophage supplementation. Unlike supplementation of $\beta$-mannanase alone (CON vs. EZ), supplementation of $\beta$-mannanase with bacteriophage (BP vs. BP_EZ) decreased the concentration of lymphocytes in blood $(p<0.01)$. When bacteriophage was not supplemented, supplementation with $\beta$-mannanase seemed to increase the N:L ratio (CON vs. EZ); however, this enhancement reduced when the diet was co-supplemented with bacteriophage (BP vs. BP_EZ, $p=0.02)$.

\section{Discussion}

Calf deaths are common during the first 3 weeks of age, resulting in significant economic losses to the cattle industry [20]. The most important causes of death in the early life of cattle are diarrhea and respiratory disease [1]. Many substances (e.g., antibiotics, probiotics, and prebiotics) 
have been proposed to reduce the calf mortality rate through direct anti-microbial effects or through improved animal health. In line with these efforts, this study investigated the effects of dietary supplementation with a commercial bacteriophage product, a commercial $\beta$-mannanase, and their associative effects on health and growth performance in male Holstein calves. This is the first study to evaluate the effect of bacteriophage supplementation and its interaction with $\beta$-mannanase supplementation in ruminants.

By the end of the experiment, 14 out of 36 calves had died up to 2 weeks after weaning and the overall calf mortality rate was $39 \%$. The major cause of death was infection by coronavirus and coccidiosis, as diagnosed by the Animal Disease Diagnostic Division of Ministry for Food, Agriculture, Forestry and Fisheries (Anyang, Gyeonggi, Korea). Although no national statistics on calf mortality are available in Korea, this value was higher than expected. Mortality rates in the early life of cattle can vary widely by season, region, and country [1]. Reported values vary from $1.5 \%$ [21] to $25 \%$ [22]. Even in developed countries, the mortality rate could be up to $31 \%$ [20].

One possible reason for the high calf mortality rate is inadequate passive transfer of immunoglobulins as a result of the insufficient consumption of colostrum. Calf immunity depends on the passive transfer of colostrum immunoglobulins from dams. However, failure of the passive transfer of immunoglobulins was reported in a considerable proportion of dairy calves [23], which occurred even when the calves remained with their dam after birth [24]. Insufficient passive transfer of immunoglobulins is associated with decreases in morbidity and mortality before weaning and during the feeding period [23]. At the time when this trial was conducted, the price of male Holstein calves was so low that many dairy farmers paid little attention to the supply of adequate amounts of colostrum to male calves. The mean $( \pm \mathrm{SD})$ serum IgG concentration of the calves, measured by 
ELISA on the day the experiment, was initiated was $10.8( \pm 3.34 \mathrm{~g} / \mathrm{L})$. This implied that the passive transfer of IgG was inadequate [ $<16 \mathrm{~g} / \mathrm{L}$; [25]], probably due to insufficient consumption of colostrum after birth.

The cold weather may be another reason for the high calf mortality rate. The experiment was conducted between January and March in an unusually cold winter. The weekly mean average (minimum) daily temperature during the 2 weeks before weaning, 1 week before weaning, 1 week after weaning, and 2 weeks after weaning were $-2.2^{\circ} \mathrm{C}(-5.8), 1.9^{\circ} \mathrm{C}(-2.7),-4.1^{\circ} \mathrm{C}(-8.5)$, and $0.1^{\circ} \mathrm{C}(-4.8)$, respectively. To maintain the indoor temperature, ventilation was relatively poor. Calf mortality rate is higher in winter than in summer [1,3] and poor ventilation is known to increase the calf mortality rate during cold winters [4].

Supplementation of diets with bacteriophage numerically decreased the calf mortality rate. The mortality rate in the unsupplemented group was 50\%, while in the supplemented group it was $28 \%$. Although statistical significance was not attained, which was likely due to the insufficient number of experimental units, bacteriophage supplementation tended to increase the odds ratio of survival of calves when the effect of initial BW was considered as a covariate. Supplementation of diets with bacteriophage also suppressed the population of E. coli (3.5 versus $4.7 \log \mathrm{CFU} / \mathrm{g})$ at 1 week after weaning, when four calves died in the bacteriophage unsupplemented group and one calf died in the bacteriophage supplemented group. Studies have shown that the population of E. coli, Salmonella spp., and C. perfringens in feces is associated with the survival rate of young ruminants $[2,26]$.

The use of bacteriophages as bacteria-control agents has been proposed in several studies. Inoculation of phage in sheep decreased populations of E. coli $\mathrm{O} 157: \mathrm{H} 7$ in the rumen, cecum, and 
rectum [27]. When challenged with pathogens, application of pathogen-specific bacteriophages decreased the number of intestinal pathogens and reduced mortality in chickens [28]. Supplementation of commercial feed additive with bacteriophages has reduced fecal E. coli counts in laying hens [29], broilers [30], and pig [31]. However, increased E. coli counts following supplementation have also been reported in laying hens [32].

Although supplementation with bacteriophages may improve the health status of calves, it may not increase their growth performance. In the present study, the growth of calves was not affected by bacteriophage supplementation. Inconsistent effects of bacteriophage supplementation have been reported on the growth of farm animals. In pigs, DMI, ADG, and feed efficiency were not improved by bacteriophage supplementation at $0.5 \mathrm{~g} / \mathrm{kg}$ although apparent total tract digestibility (ATTD) of DM and nitrogen were increased [31]. Kim, et al. [33] and Hosseindoust, et al. [34] also reported that 1.0 and $1.5 \mathrm{~g} / \mathrm{kg}$ bacteriophage had significantly improved ADG and fecal score of pigs. Bacteriophage supplementation did not improve the performance of chickens. No significant differences in growth and ATTD of nutrients were observed in broilers [30]. Little improvement in laying performance and egg quality was observed following supplementation in laying hens [32].

Co-supplementation of $\beta$-mannanase and bacteriophage seemed to alter the inflammatory response of calves, although changes in hematological parameters are hard to interpret due to large variations among individual animals. When both bacteriophage and $\beta$-mannanase supplementation were provided, a reduction in the lymphocyte count without an increase in the neutrophil count was observed. This may imply that chronic inflammation was reduced, although the mode of action is not clear. Chronic viral infections, inflammation, and autoimmune diseases increase the numbers 
of both neutrophils and lymphocytes [35]. Both neutrophil and lymphocyte counts were also increased in vaccinated animals [36]. Although temporary decreases in the number of lymphocytes can occur [37], this may not be the case in the present study since the lymphocyte counts were measured six times throughout the 10-week experimental period, and a concurrent decrease in the number of neutrophils was not observed. Stress may also lymphocyte counts to decrease; however, under stressed situations, the number of neutrophils is generally increased [38]. Other studies reported no differences in hematological parameters following bacterial supplementation in pigs [31] and broilers [30].

Conversely, $\beta$-mannanase supplementation increased BWG $(P=0.018)$. Compared with the unsupplemented group, the $\beta$-mannanase supplemented group showed a 1.3-fold higher BWG (3.05 versus $4.09 \mathrm{~kg} /$ week). Numerous studies in monogastric animals have reported that $\beta$ mannanase supplementation improved feed utilization and growth performance in broilers [10,39] and pigs $[12,40]$. Positive effects of $\beta$-mannanase supplementation on growth performance have also been reported in ruminants. Inclusion of $\beta$-mannanase in the starter feed tended to improve the feed efficiency of calves [16]. In addition, $\beta$-mannanase supplementation improved ADG, feed efficiency, and nitrogen retention in growing goats [14]. In dairy cows, the supplementation of $\beta$ mannanase has increased the feed efficiency with lowering somatic cell count [15].

The mechanism of growth improvement in response to $\beta$-mannanase supplementation in ruminants remains to be determined. In monogastric animals, $\beta$-mannanase supplementation has been proposed to improve growth performance by improving nutrient digestibility and utilization in broilers and in pigs $[12,41]$. Another proposed mechanism of action of $\beta$-mannanase supplementation is associated with mannan oligosaccharides, which are released following the 
breakdown of $\beta$-mannan in the diet and may stimulate the innate immune system of animals [10]. In ruminants, however, Lee, Seo, Jung, Lee, Lee and Seo [14] observed a decrease in nutrients digestibility and proposed that increased growth following $\beta$-mannanase supplementation might be associated with improved nitrogen metabolism in goats. Furthermore, $\beta$-mannanase supplementation alone did not alter the innate immune system in the present study. Further studies are needed to obtain a better understanding of the mechanism of action of $\beta$-mannanase supplementation in ruminants.

\section{Conclusion}

Supplementation of feed with bacteriophage may have a positive effect on calf survival rate but not on growth performance. The levels of some pathogenic bacteria (e.g., E. coli) may be reduced following bacteriophage supplementation. $\beta$-mannanase supplementation, on the other hand, may increase the growth rate and intake of a starter feed in calves. No synergistic effects were observed between the two dietary supplements on intake, growth performance, and mortality of calves, although a reduction in the lymphocyte count without an increase in the neutrophil count was observed when the diet was supplemented with both bacteriophage and $\beta$-mannanase. 
1 Table 2. The effects of bacteriophage and $\beta$-mannanase supplementation on feed intake and growth performance in male Holstein calves

\begin{tabular}{|c|c|c|c|c|c|c|c|c|c|c|}
\hline \multirow[b]{3}{*}{ Item $^{2}$} & \multirow[b]{3}{*}{$\mathbf{n}$} & \multirow{2}{*}{\multicolumn{4}{|c|}{ Treatment $^{1}$}} & \multirow[b]{3}{*}{ SEM } & \multicolumn{4}{|c|}{$P$-value } \\
\hline & & & & & & & \multirow[b]{2}{*}{ Overall } & \multicolumn{3}{|c|}{ Contrast } \\
\hline & & CON & $\mathbf{E Z}$ & BP & BP_EZ & & & $\beta$-mannanase & Bacteriophage & Interaction \\
\hline \multicolumn{11}{|l|}{$\mathrm{BW}, \mathrm{kg}$} \\
\hline Initial BW & 36 & 44 & 47 & 44 & 45 & 2.7 & 0.84 & 0.40 & 0.77 & 0.80 \\
\hline $\mathrm{BW}$ at weaning & 29 & 52 & 55 & 50 & 56 & 3.4 & 0.56 & 0.18 & 0.81 & 0.61 \\
\hline Final BW & 22 & 87 & 99 & 77 & 89 & 7.3 & 0.16 & 0.08 & 0.17 & 0.99 \\
\hline Average daily gain, $g$ & 22 & 569 & 638 & 451 & 587 & 73.7 & 0.21 & 0.13 & 0.21 & 0.61 \\
\hline \multicolumn{11}{|l|}{ Intake, $\mathrm{g} / \mathrm{d}$} \\
\hline DMI & 22 & 1,612 & 1,834 & 1,402 & 1,624 & 149.6 & 0.18 & 0.11 & 0.14 & 1.00 \\
\hline Concentrate DMI & 22 & 802 & 993 & 759 & 921 & 71.0 & 0.06 & 0.01 & 0.46 & 0.82 \\
\hline Forage DMI & 22 & 700 & 715 & 538 & 590 & 92.2 & 0.34 & 0.68 & 0.07 & 0.82 \\
\hline Feed Efficiency ${ }^{3}$ & 22 & 0.36 & 0.32 & 0.35 & 0.36 & 0.032 & 0.60 & 0.40 & 0.59 & 0.30 \\
\hline
\end{tabular}

$2 \quad{ }^{1} \mathrm{CON}$ : control calf starter; EZ: control diet supplemented with $1 \mathrm{~g} / \mathrm{kg} \beta$-mannanase; BP: control diet supplemented with $1 \mathrm{~g} / \mathrm{kg}$ bacteriophage; BP EZ: control

3 diet supplemented with $1 \mathrm{~g} / \mathrm{kg}$ bacteriophage and $1 \mathrm{~g} / \mathrm{kg} \beta$-mannanase.

$4 \quad{ }^{2} \mathrm{BW}$ : body weight, DMI: dry matter intake

$5 \quad{ }^{3}$ Average daily gain $(\mathrm{g}) / \mathrm{DMI}(\mathrm{g})$ 
7 Table 3. The effects of bacteriophage and $\beta$-mannanase supplementation on hematological responses in Holstein calves. Means of five 8 samples are presented (at weaning and at 1,2, 5, and 8 weeks after weaning)

\begin{tabular}{|c|c|c|c|c|c|c|c|c|c|}
\hline \multirow[b]{3}{*}{ Item $^{2}$} & \multirow{2}{*}{\multicolumn{4}{|c|}{ Treatments $^{1}$}} & \multirow[b]{3}{*}{ SEM } & \multicolumn{4}{|c|}{$P$-value } \\
\hline & & & & & & \multirow[b]{2}{*}{ Overall } & \multicolumn{3}{|c|}{ Contrast } \\
\hline & $\mathrm{CON}$ & $\mathbf{E Z}$ & $\mathbf{B P}$ & BP_EZ & & & $\beta$-mannanase & Bacteriophage & Interaction \\
\hline \multicolumn{10}{|l|}{ Leukocytes } \\
\hline $\mathrm{WBC}, 10^{3} / \mathrm{uL}$ & 7.6 & 8.7 & 7.7 & 9.2 & 0.53 & 0.66 & 0.75 & 0.76 & 0.24 \\
\hline Lymphocytes, $10^{3} / \mathrm{uL}$ & 3.2 & 3.1 & 3.2 & 2.9 & 0.16 & 0.07 & 0.66 & 0.94 & $<0.01$ \\
\hline Monocytes, $10^{3} / \mathrm{uL}$ & 0.75 & 0.93 & 0.74 & 0.76 & 0.111 & 0.28 & 0.22 & 0.26 & 0.29 \\
\hline Neutrophils, $10^{3} / \mathrm{uL}$ & 2.3 & 2.2 & 2.3 & 2.4 & 0.12 & 0.18 & 0.68 & 0.71 & 0.03 \\
\hline Eosinophils, $10^{3} / \mathrm{uL}$ & 0.44 & 0.47 & 0.46 & 0.57 & 0.068 & 0.27 & 0.19 & 0.64 & 0.16 \\
\hline Basophils, $10^{3} / \mathrm{uL}$ & 0.02 & 0.03 & 0.03 & 0.02 & 0.004 & 0.15 & 0.40 & 0.04 & 0.56 \\
\hline $\mathrm{N}: \mathrm{L}$ & 0.81 & 0.93 & 0.81 & 0.91 & 0.13 & 0.08 & 0.48 & 0.46 & 0.02 \\
\hline \multicolumn{10}{|l|}{ Erythrocytes } \\
\hline $\mathrm{RBC}, 10^{6} / \mathrm{uL}$ & 7.1 & 7.3 & 7.5 & 6.8 & 0.31 & 0.53 & 0.66 & 0.31 & 0.35 \\
\hline $\mathrm{MCV}, \mathrm{fL}$ & 35.6 & 34.0 & 35.5 & 34.2 & 0.71 & 0.23 & 0.26 & 0.56 & 0.10 \\
\hline HCT, \% & 25.1 & 25.3 & 26.3 & 23.4 & 1.16 & 0.58 & 0.96 & 0.45 & 0.25 \\
\hline
\end{tabular}




\begin{tabular}{lccccccccc}
\hline MCH, pg & 12.0 & 11.8 & 12.0 & 11.9 & 0.16 & 0.85 & 0.49 & 0.57 & 1.00 \\
MCHC, g/dL & 34.2 & 34.8 & 34.5 & 35.7 & 0.51 & 0.78 & 0.88 & 0.72 & 0.34 \\
Hgb, g/dL & 9.3 & 8.5 & 8.8 & 8.2 & 0.59 & 0.41 & 0.30 & 0.59 & 0.22 \\
RDW, \% & 29.0 & 19.3 & 20.5 & 21.3 & 4.58 & 1.00 & 0.87 & 0.98 & 0.94 \\
Thrombocytes & & & & & & & & 0.36 & 0.41 \\
PLT, 106/uL & 2.3 & 2.5 & 2.5 & 2.4 & 0.24 & 0.61 & 0.48 & 0.33 \\
MPV, fl & 16.2 & 16.8 & 16.7 & 16.7 & 0.37 & 0.67 & 0.83 & 0.85 \\
Total protein, mg/dL & 6.1 & 5.9 & 6.1 & 6.3 & 0.18 & 0.84 & 0.47 & 0.62 \\
BUN, mg/dL & 11.5 & 9.5 & 12.0 & 12.1 & 0.70 & 0.56 & 0.65 & 0.29 & 0.40 \\
Glucose, mg/dL & 68.7 & 74.3 & 64.1 & 63.1 & 3.51 & 0.72 & 0.29 & 0.93 \\
\hline
\end{tabular}

$9 \quad{ }^{1} \mathrm{CON}$ : control calf starter; EZ: control diet supplemented with $1 \mathrm{~g} / \mathrm{kg} \beta$-mannanase; BP: control diet supplemented $1 \mathrm{~g} / \mathrm{kg}$ bacteriophage; BP_EZ: control diet 10 supplemented with $1 \mathrm{~g} / \mathrm{kg}$ bacteriophage and $1 \mathrm{~g} / \mathrm{kg} \beta$-mannanase.

$11 \quad{ }^{2}$ WBC: white blood cell; N:L: neutrophil to lymphocyte ratio; RBC: red blood cell; MCV: mean cell volume; HCT: hematocrit; MCH: mean cell hemoglobin; MCHC:

12 mean corpuscular hemoglobin concentration; Hgb: hemoglobin; RDW: red blood cell distribution width; PLT: platelets; MPV: mean platelet volume; BUN: blood

13 urea nitrogen. 


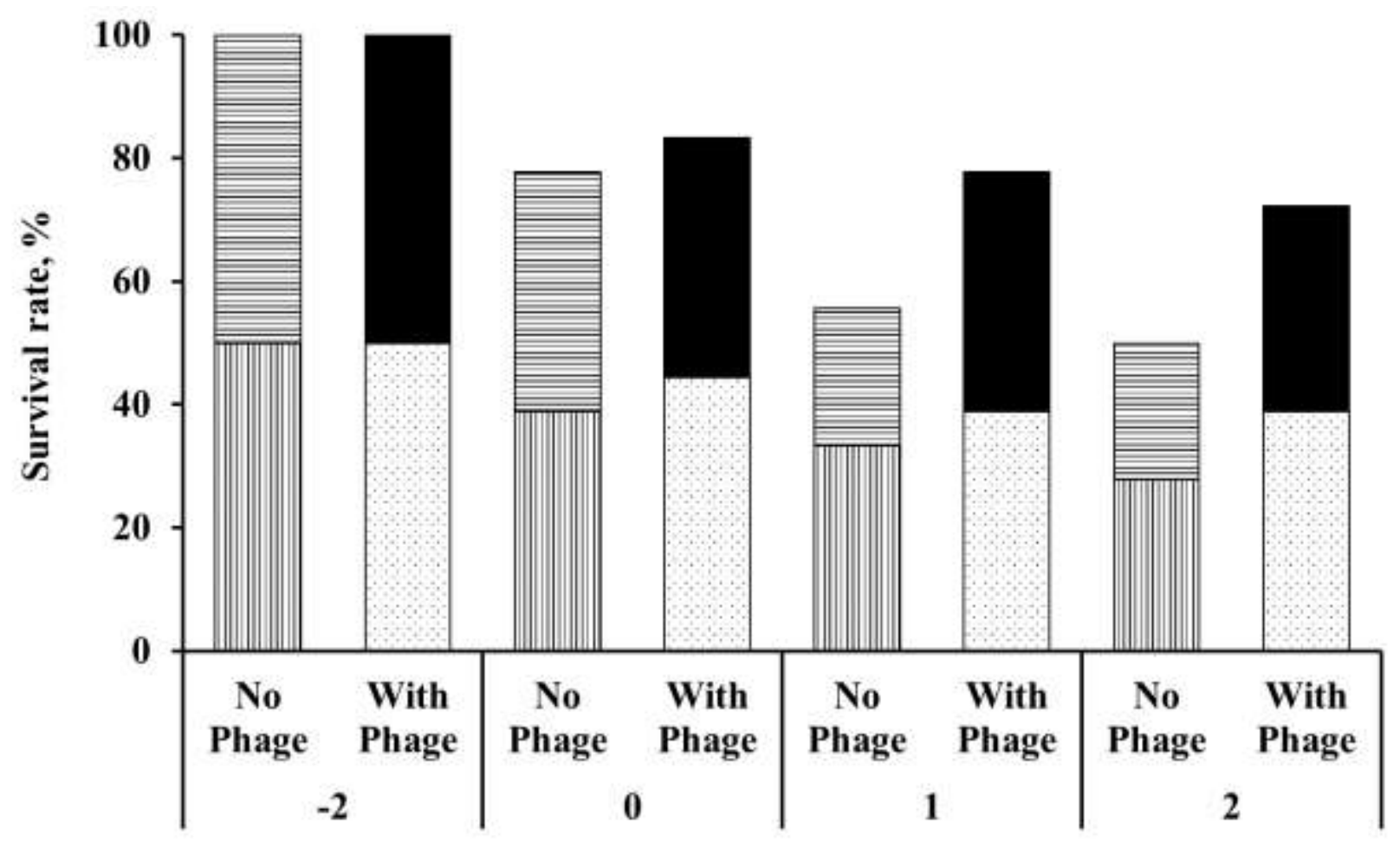

\section{Weeks relative to weaning}

15 Figure 1. Calf survival rate. Striped bars and dotted or solid bars represent the survival rate in the

16 bacteriophage unsupplemented group (i.e., control [vertical stripe] and $\beta$-mannanase supplementation

17 [horizontal stripe]) and the bacteriophage supplemented group (i.e., bacteriophage [dotted] and

18 bacteriophage plus $\beta$-mannanase supplementation [solid]), respectively. No further calf deaths

19 occurred from two weeks after weaning. 


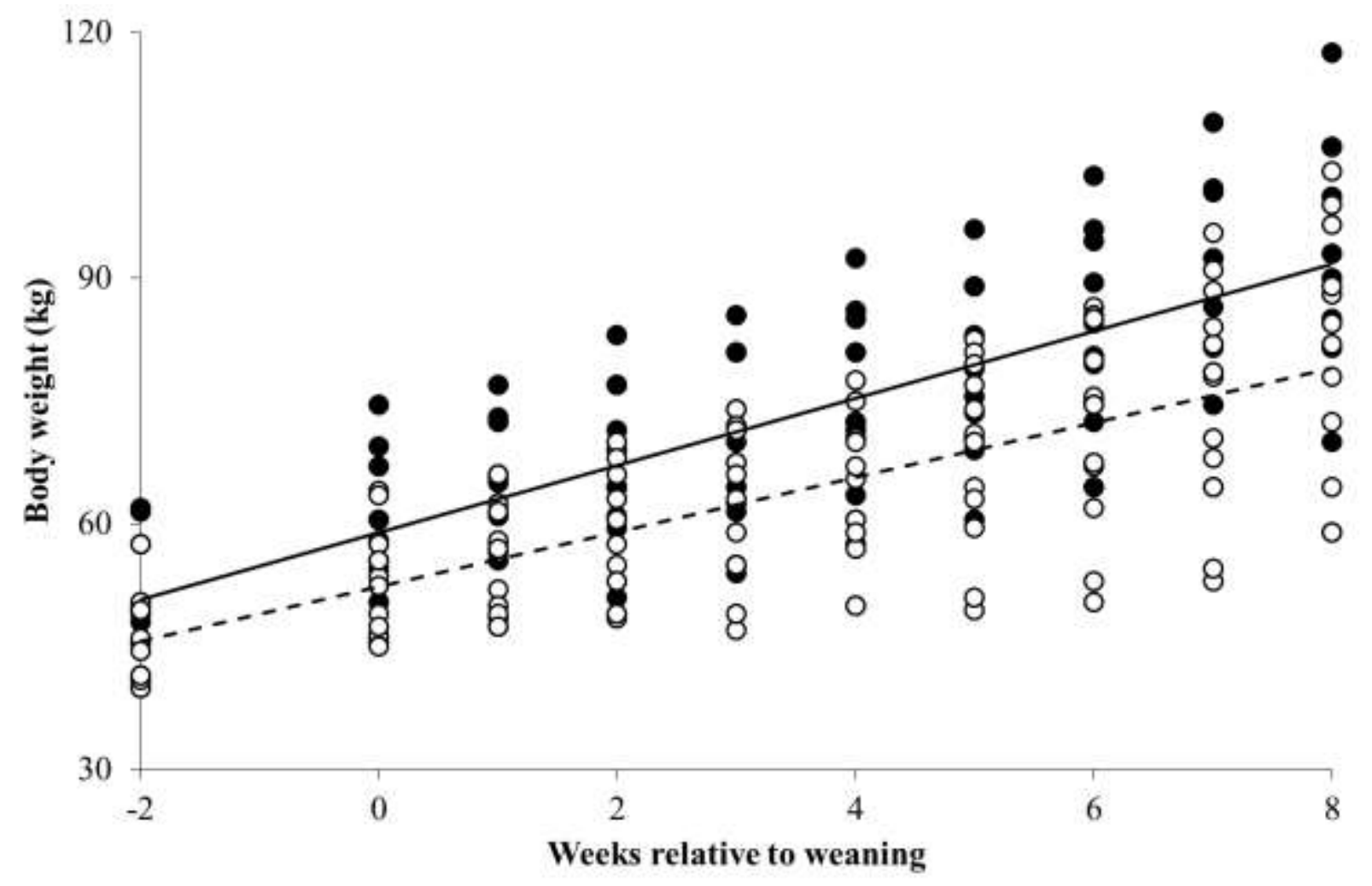

22 Figure 2. Body weight (BW) of calves at weeks relative to weaning. The open circle (o) and dotted

23 line represent $\mathrm{BW}$ of the $\beta$-mannanase unsupplemented group (i.e. control and bacteriophage

24 supplementation) and the closed circle $(\bullet)$ and solid line represent BW of the $\beta$-mannanase

25 supplemented group (i.e., $\beta$-mannanase and bacteriophage plus $\beta$-mannanase supplementation).

26

27 


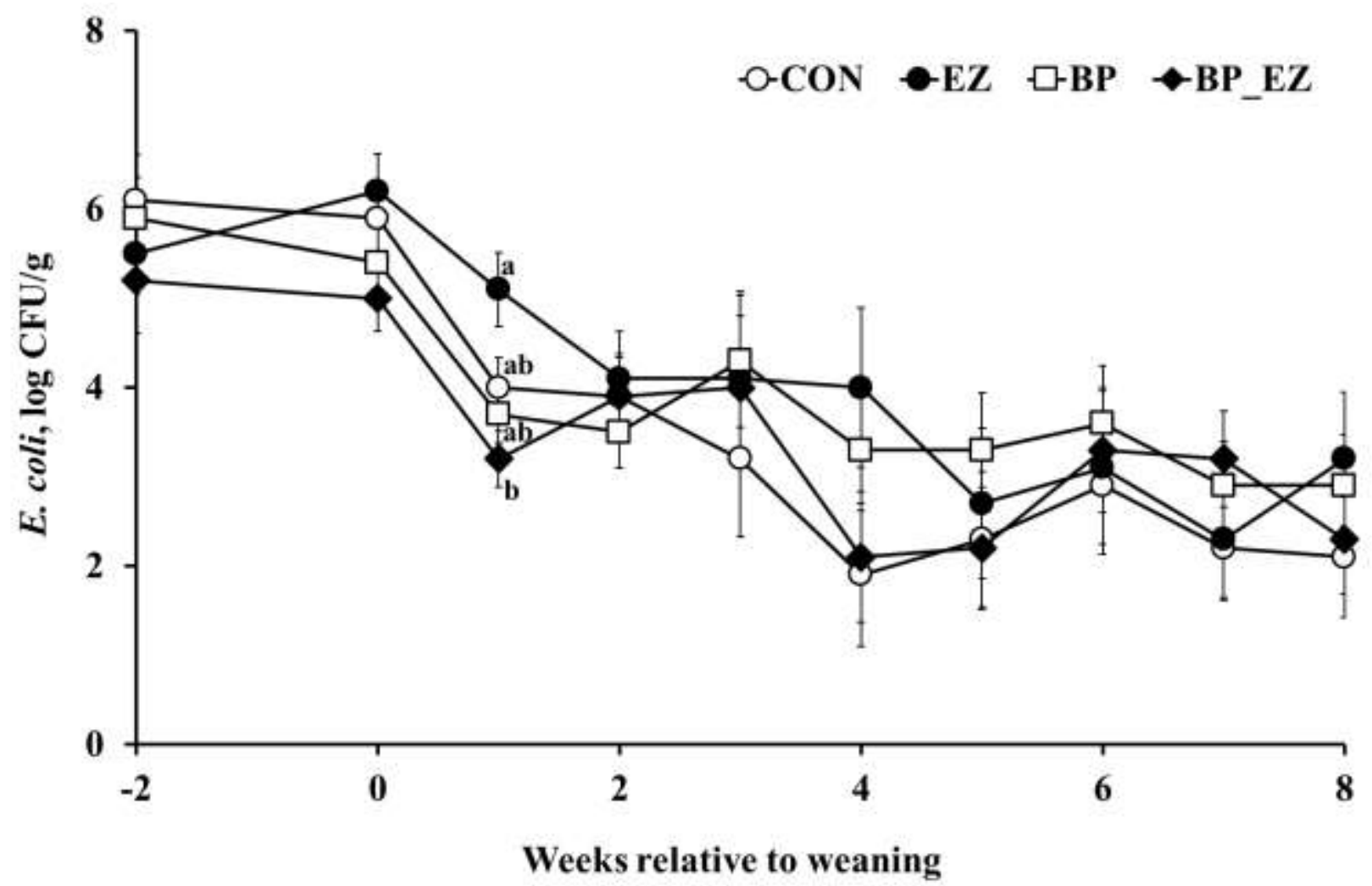

Figure 3. Changes in the number (log CFU/g) of Escherichia coli in calf feces. The open-circle (o),

30 closed-circle $(\bullet)$, open-square $(\square)$, and closed-diamond $(\bullet)$ represent least square means of the control,

$31 \beta$-mannanase supplementation, bacteriophage supplementation, and bacteriophage plus $\beta$ -

32 mannanase supplementation groups, respectively. Error bars represent standard errors of the means at

33 each week. ${ }^{\mathrm{a}, \mathrm{b}}$ Means that do not have common superscripts $\operatorname{differ}(P<0.01)$. 
35 Author Contributions: Conceptualization: J.-J.L., J.-H.L. and S.S.; Methodology: S.S.;

36 Validation: S.J.; Formal Analysis: S.J. and S.S.; Investigation: S.J., J.L. and N.J.; Resources: J.-

37 J.L., J.-H.L. and D.-K.K.; Data Curation: S.J. and S.S.; Writing - Original Draft preparation: S.J.;

38 Writing - Review \& Editing: N.J., D.-K.K., E.K. and S.S.

39

40 Funding: This research was supported by the Bioindustry Technology Development Program

41 (Project No. 312030-04-3-HD060), Ministry of Agriculture, Food and Rural Affairs, Republic of

42 Korea.

43

44 Acknowledgements: The authors would like to express sincere appreciation to late Dr. Woonsu

45 Kim for his scientific assistance and friendship during the preparation of the manuscript.

46

47 Conflicts of interest: The authors declare that the research was conducted in the absence of any

48 commercial or financial relationships that could be construed as a potential conflict of interest. 
50 1. Svensson, C.; Linder, A.; Olsson, S.-O. Mortality in Swedish dairy calves and replacement

\section{References} heifers. J. Dairy Sci. 2006, 89, 4769-4777, doi:10.3168/jds.s0022-0302(06)72526-7

2. Dean-Nystrom, E.A.; Bosworth, B.T.; Cray, W.; Moon, H.W. Pathogenicity of Escherichia coli $\mathrm{O} 157: \mathrm{H} 7$ in the intestines of neonatal calves. Infect. Immun. 1997, 65, 1842-1848, doi:10.1007/978-1-4899-1828-4_5.

3. Uetake, K. Newborn calf welfare: a review focusing on mortality rates. Anim. Sci. J. 2013, 84, 101-105, doi:10.1111/asj.12019

4. Lago, A.; McGuirk, S.M.; Bennett, T.B.; Cook, N.B.; Nordlund, K.V. Calf respiratory disease and pen microenvironments in naturally ventilated calf barns in winter. J. Dairy Sci. 2006, 89, 4014-4025, doi:10.3168/jds.S0022-0302(06)72445-6.

5. Sawant, A.A.; Sordillo, L.M.; Jayarao, B.M. A survey on antibiotic usage in dairy herds in Pennsylvania. J. Dairy Sci. 2005, 88, 2991-2999, doi:10.3168/jds.S0022-0302(05)729799.

6. Gebru, E.; Lee, J.S.; Son, J.C.; Yang, S.Y.; Shin, S.A.; Kim, B.; Kim, M.K.; Park, S.C. Effect of probiotic-, bacteriophage-, or organic acid-supplemented feeds or fermented soybean meal on the growth performance, acute-phase response, and bacterial shedding of grower pigs challenged with serotype Typhimurium. J. Anim. Sci. 2010, 88, 3880-3886, doi:10.2527/jas.2010-2939.

7. Abedon, S.T.; Kuhl, S.J.; Blasdel, B.G.; Kutter, E.M. Phage treatment of human infections. Bacteriophage. 2011, 1, 66-85, doi:10.4161/bact.1.2.15845.

8. Brüssow, H. Phage therapy: the Escherichia coli experience. Microbiology. 2005, 151, 

2133-2140, doi:10.1099/mic.0.27849-0.

9. Hume, M.E. Food safety symposium: potential impact of reduced antibiotic use and the roles of prebiotics, probiotics, and other alternatives in antibiotic-free broiler production. Poult. Sci. 2011, 90, 2663-2669, doi:10.3382/ps.2010-01030.

10. Jackson, M.E.; Geronian, K.; Knox, A.; McNab, J.; McCartney, E. A dose-response study with the feed enzyme beta-mannanase in broilers provided with corn-soybean meal based diets in the absence of antibiotic growth promoters. Poult. Sci. 2004, 83, 1992-1996, doi:10.1093/ps/83.12.1992

11. Cho, J.H.; Kim, I.H. Effects of beta-mannanase supplementation in combination with low and high energy dense diets for growing and finishing broilers. Livest. Sci. 2013, 154, $137-$ 143, doi:10.1016/j.livsci.2013.03.004.

12. Yoon, S.Y.; Yang, Y.X.; Shinde, P.L.; Choi, J.Y.; Kim, J.S.; Kim, Y.W.; Yun, K.; Jo, J.K.; Lee, J.H.; Ohh, S.J., et al. Effects of mannanase and distillers dried grain with solubles on growth performance, nutrient digestibility, and carcass characteristics of grower-finisher pigs. J. Anim. Sci. 2010, 88, 181-191, doi:10.2527/jas.2008-1741.

13. Kim, J.; Ingale, S.; Lee, S.; Kim, K.; Lee, J.; Chae, B. Effects of energy levels of diet and $\beta$-mannanase supplementation on growth performance, apparent total tract digestibility and blood metabolites in growing pigs. Anim. Feed Sci. Technol. 2013, 186, 64-70, doi:10.1016/j.anifeedsci.2013.08.008.

14. Lee, J.-J.; Seo, J.; Jung, J.K.; Lee, J.; Lee, J.-H.; Seo, S. Effects of $\beta$-mannanase supplementation on growth performance, nutrient digestibility, and nitrogen utilization of Korean native goat (Capra hircus coreanae). Livest. Sci. 2014, 169, 83-87, 
doi:10.1016/j.livsci.2014.08.018.

15. Tewoldebrhan, T.; Appuhamy, J.; Lee, J.-J.; Niu, M.; Seo, S.; Jeong, S.; Kebreab, E. Exogenous $\beta$-mannanase improves feed conversion efficiency and reduces somatic cell count in dairy cattle. J. Dairy Sci. 2017, 100, 244-252, doi:10.3168/jds.2016-11017.

16. Lee, S.-Y.; Lee, S.-M.; Kim, J.-H.; Ki, K.-S.; Kim, H.-S.; Kam, D.-K.; Lee, J.-H.; Lee, J.J.; Bae, G.-S.; Seo, S.-W. Effect of $\beta$-mannanase $\left(\mathrm{CTCZYME}^{\circledR}\right)$ on the growth of young calf. CNU J. Agri. Sci. 2010, 37, 239-243, doi:10.7744/cnujas.2010.37.2.239.

17. AOAC. Official Methods of Analysis of AOAC International, 18 ed.; Association of Official Analytical Chemists International: Gaithersburg, MD, USA, 2005.

18. Van Soest, P.J.; Robertson, J.B.; Lewis, B.A. Methods for dietary fiber, neutral detergent fiber, and nonstarch polysaccharides in relation to animal nutrition. J. Dairy Sci. 1991, 74, 3583-3597, doi:10.3168/jds.S0022-0302(91)78551-2.

19. Seo, S.; Jeon, S.; Ha, J.K. — Editorial — Guidelines for experimental design and statistical analyses in animal studies submitted for publication in the Asian-Australasian Journal of Animal Sciences. Asian-australas. J. Anim. Sci. 2018, 31, 1381-1386, doi:10.5713/ajas.18.0468.

20. Wells, S.J.; Dargatz, D.A.; Ott, S.L. Factors associated with mortality to 21 days of life in dairy heifers in the United States. Prev. Vet. Med. 1996, 29, 9-19, doi:10.1016/S01675877(96)01061-6.

21. Torsein, M.; Lindberg, A.; Sandgren, C.H.; Waller, K.P.; Törnquist, M.; Svensson, C. Risk factors for calf mortality in large Swedish dairy herds. Prev. Vet. Med. 2011, 99, 136-147, doi:10.1016/j.prevetmed.2010.12.001. 
115 22. Wymann, M.N.; Bonfoh, B.; Schelling, E.; Bengaly, S.; Tembely, S.; Tanner, M.; Zinsstag, J. Calf mortality rate and causes of death under different herd management systems in periurban Bamako, Mali. Livest. Sci. 2006, 100, 169-178, doi:10.1016/j.livsci.2005.08.010.

118 23. Godden, S. Colostrum management for dairy calves. Veterinary Clinics of North America: Food Animal Practice 2008, 24, 19-39, doi:10.1016/j.cvfa.2007.10.005.

120 24. Brignole, T.J.; Stott, G.H. Effect of suckling followed by bottle feeding colostrum on immunoglobulin absorption and calf survival. J. Dairy Sci. 1980, 63, 451-456, doi:10.3168/jds.S0022-0302(80)82952-3.

25. Waldner, C.L.; Rosengren, L.B. Factors associated with serum immunoglobulin levels in beef calves from Alberta and Saskatchewan and association between passive transfer and health outcomes. Can. Vet. J. 2009, 50, 275-281, doi:10.1139/cjas-2016-0055

26. Callaway, T.R.; Edrington, T.S.; Brabban, A.D.; Keen, J.E.; Anderson, R.C.; Rossman, M.L.;

Engler, M.J.; Genovese, K.J.; Gwartney, B.L.; Reagan, J.O., et al. Fecal prevalence of Escherichia coli O157, Salmonella, Listeria, and Bacteriophage Infecting E. coli O157:H7 in feedlot cattle in the Southern Plains region of the United States. Foodborne Pathog. Dis. 2006, 3, 234-244, doi:10.1089/fpd.2006.3.234.

27. Callaway, T.R.; Edrington, T.S.; Brabban, A.D.; Anderson, R.C.; Rossman, M.L.; Engler, M.J.; Carr, M.A.; Genovese, K.J.; Keen, J.E.; Looper, M.L., et al. Bacteriophage isolated from feedlot cattle can reduce Escherichia coli O157:H7 populations in ruminant gastrointestinal tracts. Foodborne Pathog. Dis. 2008, 5, 183-191, 135 doi:10.1089/fpd.2007.0057.

136 28. Berchieri Jr., A.; Lovell, M.A.; Barrow, P.A. The activity in the chicken alimentary tract of 
bacteriophages lytic for Salmonella typhimurium. Res. Microbiol. 1991, 142, 541-549, doi:10.1016/0923-2508(91)90187-F.

29. Zhao, P.Y.; Baek, H.Y.; Kim, I.H. Effects of bacteriophage supplementation on egg performance, egg quality, excreta microflora, and moisture content in laying hens. Asianaustralas. J. Anim. Sci. 2012, 25, 1015-1020, doi:10.5713/ajas.2012.12026.

30. Wang, J.P.; Yan, L.; Lee, J.H.; Kim, I.H. Evaluation of bacteriophage supplementation on growth performance, blood characteristics, relative organ weight, breast muscle characteristics and excreta microbial shedding in broilers. Asian-australas. J. Anim. Sci. 2013, 26, 573-578, doi:10.5713/ajas.2012.12544.

31. Kim, K.H.; Ingale, S.L.; Kim, J.S.; Lee, S.H.; Lee, J.H.; Kwon, I.K.; Chae, B.J. Bacteriophage and probiotics both enhance the performance of growing pigs but bacteriophage are more effective. Anim. Feed Sci. Technol. 2014, 196, 88-95, doi:10.1016/j.anifeedsci.2014.06.012

32. Kim, J.H.; Kim, J.W.; Shin, H.S.; Kim, M.C.; Lee, J.H.; Kim, G.B.; Kil, D.Y. Effect of dietary supplementation of bacteriophage on performance, egg quality and caecal bacterial populations in laying hens. Br. Poult. Sci. 2015, 56, 132-136, doi:10.1080/00071668.2014.991272.

33. Kim, J.S.; Hosseindoust, A.; Lee, S.H.; Choi, Y.H.; Kim, M.J.; Lee, J.H.; Kwon, I.K.; Chae, B.J. Bacteriophage cocktail and multi-strain probiotics in the feed for weanling pigs: effects on intestine morphology and targeted intestinal coliforms and Clostridium. Animal 2017, 11, 45-53, doi:10.1017/s1751731116001166.

34. Hosseindoust, A.R.; Lee, S.H.; Kim, J.S.; Choi, Y.H.; Noh, H.S.; Lee, J.H.; Jha, P.K.; Kwon, 
I.K.; Chae, B.J. Dietary bacteriophages as an alternative for zinc oxide or organic acids to control diarrhoea and improve the performance of weanling piglets. Veterinarni Medicina 2017, 62, doi:10.17221/7/2016-vetmed

35. Jones, M.L.; Allison, R.W. Evaluation of the ruminant complete blood cell count. Vet. Clin. North Am. Food Anim. Pract. 2007, 23, 377-402, doi:10.1016/j.cvfa.2007.07.002.

36. Jo, N.C.; Jung, J.; Kim, J.N.; Lee, J.; Jeong, S.Y.; Kim, W.; Sung, H.G.; Seo, S. Effect of vaccination against foot-and-mouth disease on growth performance of Korean native goat (Capra hircus coreanae). J. Anim. Sci. 2014, 92, 2578-2586, doi:10.2527/jas.2014-7190.

37. Sarıkaya, B.; Azkur, A.K.; Gazyagci, S. Inactivated bovine viral diarrhea virus vaccine trigger leucopenia and lymphopenia on calves. Acta Sci. Vet. 2011, 39, 994.

38. Davis, A.K.; Maney, D.L.; Maerz, J.C. The use of leukocyte profiles to measure stress in vertebrates: a review for ecologists. Funct. Ecol. 2008, 22, 760-772, doi:10.1111/j.13652435.2008.01467.

39. Li, Y.; Chen, X.; Chen, Y.; Li, Z.; Cao, Y. Effects of $\beta$-mannanase expressed by Pichia pastoris in corn-soybean meal diets on broiler performance, nutrient digestibility, energy utilization and immunoglobulin levels. Anim. Feed Sci. Technol. 2010, 159, 59-67, doi:10.1016/j.anifeedsci.2010.05.001.

40. Lv, J.; Chen, Y.; Guo, X.; Piao, X.; Cao, Y.; Dong, B. Effects of supplementation of $\beta$ mannanase in corn-soybean meal diets on performance and nutrient digestibility in growing pigs. Asian-australas. J. Anim. Sci. 2013, 26, 579, doi:10.5713/ajas.2012.12612

41. Kim, S.C.; Kim, J.W.; Kim, J.U.; Kim, I.H. Effects of dietary supplementation of bacteriophage on growth performance, nutrient digestibility, blood profiles, carcass 
characteristics and fecal microflora in broilers. Korean J. Poult. Sci. 2013, 40, 75-81,

182 doi:10.5536/kjps.2013.40.1.075

183 